\title{
An Interactive Computer Model of Two-Country Trade
}

\author{
Bill Hamlen and Kevin Hamlen
}

\begin{abstract}
We introduce an interactive computer model of two-country trade that allows students to investigate the consequences of changing economic parameters. The model is self-contained and makes no assumption concerning the existence of social welfare functions or social indifference curves. The factors of production earn incomes that lead to the demand for two goods. Students can see who are the winners and losers when going from a closed economy to an open economy. The students are able to predict the consequences and then obtain immediate feedback.
\end{abstract}

JEL classification: A22, A23, F10, F11

\section{Introduction}

The purpose of this paper is to present an interactive computer model of two-country international trade that allows students to understand the gains and losses of going from a closed economy to an open economy with international trade. Although computer models tend to make specific and sometimes simplifying assumptions, many students learn better when they are able to experiment by making predictions on the effects of changing parameters and then obtaining immediate feedback on these changes.

The model proposed is in the spirit of those computer models by Murphy (1995), Mixon and Tohamy (1999 and 2003), and Hamlen and Hamlen (2006). The model by Murphy was one of the first efforts to produce a production possibility (PP) curve using the mathematical software DERIVE. The 2003 model by Tohamy and Mixon provides an excellent presentation of international trade possibilities using the specific factor model. Its complexity, along with several restrictive assumptions, make it reasonable for a specific course in international trade but not for a general intermediate microeconomics course where PP curves and the resulting two-country international trade outcomes are just a small portion of the course contents. Hamlen and Hamlen (2006) developed the self-contained model for a single country.

In the model proposed here the simple equations used by Hamlen and Hamlen for one country are extended to two countries. The primary goal of the proposed model is to enable the student to evaluate the gains and losses of two countries, and representative individuals in these countries, when the countries go from closed economies to open economies. By changing parameters in the model the students can predict the consequences and then quickly obtain feedback on the actual outcomes within the model structure. 
The endowments of labour, $\bar{L}_{i}$, and capital stock, $\bar{K}_{i}$, in each country, $i=1,2$ are to be given changeable parameters. Representative individuals of labour income earners and capital stock income earners in each country are given homogeneous utility functions (of degree 1 ) and the parameters of these can be changed. There are the same two goods produced in each country and the two production functions in both countries are Cobb-Douglas types but returns to scale need not be constant. Many interesting details can be examined by changing the parameters. The students can learn to predict which goods will increase and decrease in each country when trade is opened up. They can also learn to predict whether labour or capital stock owners will benefit in each country when free trade is made available. One of the most important learning lessons for the students is to dispel the notion that everyone is made happier by shifting from a closed economy to an open economy and that social welfare is always improved.

In section two the usual textbook presentation of the benefits of international trade are described along with the weaknesses in the presentation. In the third section, using the basic algebra of international trade, the simple two-country model is presented in a way that can be programmed in Excel, readily allowing student access for experimentation. In the fourth section the methodology for successfully using the model in the classroom is described. This is followed by the conclusion.

\section{The textbook case}

One of the current authors remembers attending a seminar in the early to mid 1970s when the speaker, Professor Ronald Jones, began by saying that while most professors who teach principles of economics claim that all countries are better off when they engage in international trade and, in fact, everyone benefits by having international trade, it is, in reality, not true. Since many of those in attendance were not international trade specialists there was a general sense of surprise and bewilderment. Most had been taught a simplistic untruth that everyone benefits by moving from a closed economy to one of free trade. This untruth is still frequently passed on in today's principles of economics textbooks.

Figure 1 illustrates an example of the familiar textbook presentation of the benefits of international trade. In the specific example given it is assumed that there are two countries with the same factor endowments but with different social welfare functions, i.e. different social indifference curves. Without international trade (Figure 1 ) each country maximises its social welfare and finds an optimal place on its own respective PP curve. The domestic price ratios for each country are shown and are different for different countries with good $Q$ being relatively more valuable in country 1 and good $Y$ relatively more valuable in country 2 . Figure 1 also shows the result after international trade takes place. Each country can reach a higher social indifference curve. In this case, country 1 shifts to producing more of good $Y$ and less of good $Q$ while country 2 shifts production to more of good $Q$ and less of good $Y$. A common international price ratio, such as the one shown, is established and it is required that imports and exports match for both countries. In Figure 1 this implies that $c b=a d$ and $b a=d e$. 
Figure 1: Trade with a Social Indifference Curve

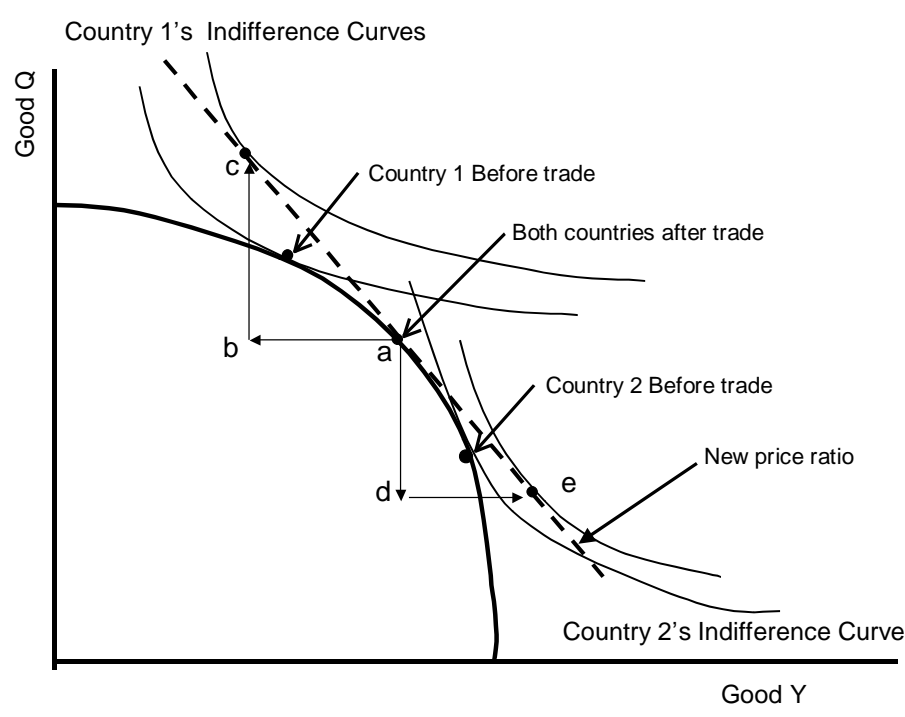

The solution shown in Figure 1 depends on the existence of well-behaved social indifference curves such as those shown. Fortunately or unfortunately, as Kenneth Arrow (1951) pointed out long ago, social welfare functions with well-behaved social indifference curves such as in Figures 1 probably do not exist, except possibly in the case of one indicating the tastes and preferences of an absolute dictatorship.

Perhaps the closest thing to a known social welfare function (SWF) is that which was derived by Negishi (1960) for a perfectly competitive economy. Negishi proved that under the most common assumptions for a perfectly competitive economy the society "acts as if" it is maximising a specific SWF, subject to the standard supply and demand conditions and production technologies. The Negishi function is the weighted sum of the utility functions of the respective households with the weights equal to the reciprocals of their marginal utilities of income. This SWF cannot, of course, satisfy all of Arrow's (1951) desirable attributes for a social welfare function, e.g. transitivity and completeness. This is because Negishi's SWF is not independent of the PP curve. The weights placed on individual households in the SWF, i.e. the reciprocals of the marginal utilities of income, are directly dependent on the production processes. Nevertheless, when a society chooses a free enterprise, competitive economy, based possibly on its attributes of freedom and efficiency, it is implicitly acting "as if" it seeks to maximise the Negishi SWF. Thus, when comparing two states of the economy in a competitive model the changes in the Negishi SWF can be used as a measure of gain or loss for the entire country. The Negishi SWF, however, cannot be used to determine the optimal point on the production possibility curve. It can only be measured after the optimal point is obtained through other demand and supply conditions.

\section{The equations of the two-country model}

In 1971 both Ronald Jones (1971) and Paul Samuelson (1971) worked out the simple algebra of a closed two-good economy. Every point on a production possibility curve generates incomes to the factors of production. These, in turn, create demands for the goods produced. The point on a production possibility curve where supply and demand are equal for both goods is the economic equilibrium solution. No SWF or social indifference curves such as in Figure 1 are needed to determine the optimal point on the production possibility curve. When this closed algebraic system is applied to two countries with free trade the solution requires that the total demand equals total supply and that there be a single international relative price ratio. By making some specific assumptions on individual preferences 
the model can be closed and appropriate search procedures used to find the solutions for closed economies and open economies. In fact, the equations necessary to solve a specific problem can be simulated in an available software package such as Excel.

In the current case some, but not all, of the equations related to deriving the PP curve for a single country are found in Hamlen and Hamlen (2006). These equations are combined and expanded here for a two-country trade model. The Excel model allows students to experiment and see for themselves the possible outcomes under different scenarios. The model does not require that there exists any particular "returns to scale" in production. It does require that there be no increasing "returns" to any factor of production but this is a standard assumption. Factors of production, i.e. labour and capital stock, are assumed to receive the value of the marginal physical product of the last unit hired but when the returns to scale are not unitary the difference, plus or negative, is assumed to go to the owners of the capital stock.

One immediate result is that going from a closed economy with no international trade to an open economy with international trade generally helps some factors of production but hurts others. This does not imply that those gaining could not potentially compensate the losers but, if so, such compensation rarely occurs. And if some policy of compensation for accepting international trade was added to the competitive model the new behaviour rules for the participants would have to be derived. The competitive results derived by Negishi would no longer hold.

\section{The Production Equations}

Each country is assumed to produce the same two goods, good $Q_{i}$ and good $Y_{i}, i=1,2$. These are produced using Cobb-Douglas production functions:

$$
Q_{i}=A_{i} L_{i}^{\alpha_{i}} K_{i}^{\beta_{i}}, i=1,2
$$

and:

$$
Y_{i}=B_{i}\left(\bar{L}_{i}-L_{i}\right)^{a_{i}}\left(\bar{K}_{i}-K_{i}\right)^{b_{i}}, i=1,2
$$

where $\bar{L}_{i}$, and $\bar{K}_{i}, i=1,2$ are the endowments of labour and capital in each country.

To obtain the PP curve in each country, it is useful to make most other variables a function of one of the inputs, say $L_{i}, i=1,2$. To obtain the Edgeworth-Bowley contract relationship in each country, the total differentials of (1) and (2) are taken and $d Q_{i}$ and $d Y_{i}$ are set equal to zero. Then the slopes of the isoquants, $d K_{j i} / d L_{j i}, j=1,2$ and $i=1,2$ for both goods, $j=1,2$ are obtained and set equal to each other for each country. From this we obtain the relationships:

$$
\left(\alpha_{i} / \beta_{i}\right)\left(K_{i}^{1-\beta_{i}} / L_{i}^{1-\alpha_{i}}\right)=\left(a_{i} / b_{i}\right)\left[\left(\bar{K}_{i}-K_{i}\right)^{1-b_{i}} /\left(\bar{L}_{i}-L_{i}\right)^{1-a_{i}}\right], i=1,2
$$

For any value of $L_{i}, i=1,2$ and production parameters, $\alpha, b, a, b, A$ and $B$, a value of $K_{i} l=1,2$ can be obtained that solves equation (3). This provides the relationship $K_{i}=g_{i}\left(L_{i}\right), i=1,2$. Therefore we can graph the following equations to obtain the PP curves in each country:

$$
Q_{i}\left(L_{i}\right)=A_{i} L_{i}^{\alpha_{i}}\left[g_{i}\left(L_{i}\right)\right]^{\beta_{i}}, i=1,2
$$

and: 


$$
Y_{i}\left(L_{i}\right)=B_{i}\left(\bar{L}_{i}-L_{i}\right)^{a_{i}}\left[\bar{K}_{i}-g_{i}\left(L_{i}\right)\right]^{b_{i}}, i=1,2
$$

The slopes of the PP curves are needed to construct the price ratios and to find the final solution after the countries move from closed economies to open economies. Using equations (4) and (5) the increments along the PP curves can be obtained. These are given by:

$$
-\left(P_{Y_{i}} / P_{Q_{j}}\right)=\left[\Delta Q_{i}\left(L_{i}\right) / \Delta Y_{i}\left(L_{i}\right)\right], i=1,2
$$

Since only the relative prices are relevant $P_{Q_{i},} i=1,2$ is set equal to 1 .

\section{Demand Equations}

In each country there is assumed to be two groups of individuals, those who derive their income from labour and those who derive their income from owning the capital stock. We allow each group to have a single representative utility function. This assumption can be further relaxed to allow for subgroups, although there is not much to be gained for such an extension. For the utility functions we use simple homogeneous utility functions of degree 1 . These are given by:

$$
U_{i}\left(\text { Labour }_{i}\right)=D_{i} Q_{i}^{s_{i}} Y_{i}^{t_{i}}, D_{i}, s_{i}, t_{i}>0, s_{i}+t_{i}=1, i=1,2
$$

and:

$$
V_{i}\left(\text { Capital }_{i}\right)=E_{i} Q_{i}{ }^{w_{i}} Y_{i}^{x_{i}}, E_{i}, w_{i}, x_{i}>0, w_{i}+x_{i}=1, i=1,2
$$

The indirect utility functions are easily derived and are given by:

$$
U_{i}\left(\text { Labour }_{i}\right)=M_{L i}^{s_{i}+t_{i}}\left[P_{Q i}{ }^{-s_{i}} P_{Y_{i}}{ }^{-t_{i}}\left(s_{i}+t_{i}\right)^{-s_{i}-t_{i}} s_{i}^{s_{i}} t_{i}^{t_{i}}\right], i=1,2
$$

and:

$$
V_{i}\left(\text { Capital }_{i}\right)=M_{K i}{ }^{w_{i}+x_{i}}\left[P_{Q i}{ }^{-w_{i}} P_{Y_{i}}{ }^{-x_{i}}\left(w_{i}+x_{i}\right)^{-w_{i}-x_{i}} w_{i}^{w_{i}} x_{i}^{x_{i}}\right], i=1,2
$$

where $M_{L i}$ and $M_{K i}$ are the incomes of the labour and capital stock owners in each country respectively.

The Negishi (competitive) SWF in each country is given by:

$$
W_{i}=\left(1 / \lambda_{L i}\right) U_{i}\left(\text { Labour }_{i}\right)+\left(1 / \lambda_{G i}\right) V_{i}\left(\text { Capital }_{i}\right), i=1,2
$$

where $\lambda_{L i}$ and $\lambda_{C i}$ are the marginal utilities of income for labour and capital stock owners in country $i$ respectively. These can be calculated by the well-known first order condition that $\partial U_{i}($ Labour $) / \partial Q_{i}=\lambda_{i} P_{Q i i}$ and $\partial V_{i}\left(\right.$ Capital $\left._{i}\right) / \partial Q_{i}=\lambda_{i} P_{Q j}$

Next we assume that there is a competitive market for labour and thus given the Cobb-Douglas production functions we obtain income to labour as:

$$
M_{L i}=\alpha_{i} Q_{i}+a_{i} P_{Y i} Y_{i}, i=1,2 \text { and } P_{Q j}=1
$$

The income to capital stock owners is assumed to be equal to the value of output not claimed by labour. When there are decreasing returns to scale in both goods this solution provides a surplus beyond the perfectly competitive value. Thus the income to capital stock owners in each country is: 


$$
M_{K i}=\left(1-\alpha_{i}\right) Q_{i}+\left(1-a_{i}\right) P_{Y_{i}} Y_{i}, i=1,2
$$

The income equations (12) and (13) along with the first order conditions for the optimal product selection provide the demand equation for one of the goods, e.g. good $Y_{i}$, as a function of labour, $L_{i}$. This demand can be set equal to the supply $Y_{i}$ to yield the following equilibrium condition for each closed country:

$$
\frac{\left[\alpha_{i} Q_{i}\left(L_{i}\right)+a_{i} Y_{i}\left(L_{i}\right)\left(P_{Y_{i}} / P_{Q_{j}}\right)\right]}{\left[\left(s_{i} / t_{i}\right)+1\right]}+\frac{\left[\left(1-\alpha_{i}\right) Q_{i}\left(L_{i}\right)+\left(1-a_{i}\right) Y_{i}\left(L_{i}\right)\left(P_{Y_{i}} / P_{Q_{j}}\right)\right]}{\left[\left(w_{i} / x_{i}\right)+1\right.}-Y_{i}\left(L_{i}\right)=0
$$

By varying $L_{i}$ from 0 to $\bar{L}_{i}, i=1,2$ the location on the PP curve where the total supply equals the total demand for both goods can be obtained. At this point one can also evaluate the utility achieved by labour and capital stock owners using equation (9) and (10). This all accomplished for two closed economies.

The next problem requires obtaining the open economy solution. In this case the total demand must equal the total supply there must be a common price ration. This can be accomplished using equation (14) but combining the demands and supplies for both countries. Then using a search routine it is possible to find solution where the total demand for goods equals the total supply (equation 14) and there is a single price ratio between countries. Incomes for all factors of production in each country are re-calculated using the new international price ratio and equations (12) and (13). Next the utility for each representative in each country can be calculated. This is the open economy solution. We know from basic international trade theory, of course, that there can be situations where international trade between two counties has only a boundary solution or no unique solution. Most of the situations used in the model presented above do not run into that problem.

Comparing the autarky and open trade solution using the model allows not only the differences in production in each country to be examined but also the differences in happiness (utility) of the representative individuals in each country as well as the changes in the Negishi SWF.

\section{Use of the model}

The two-country trade model has been used extensively in an advanced (senior) undergraduate course as well as less extensively in required core MBA courses in economics. It was used along with many other similar models developed primarily in Excel. In fact, use of such models was the focus of the advanced undergraduate course. The answer to an important pedagogical question was sought: Does use of interactive computer models facilitate the learning experience? The computer models are not used alone without the basic theory related to the models.

The first time the course was taught, only average student evaluations were obtained (3.5 out of 5 with 5 being the top evaluation and the question being: "how much did you gain from this course?") Since it was an experimental course the students seemed willing to share their views. It turned out that the particular method of using the interactive computer models was the primary fault. The models were initially presented to the students and then they were given lengthy assignments to complete using the models. They would change the parameters and then write down the resulting changes in the outcomes of the models. Students admitted that, given the demands on their time in other courses, they found it expedient and optimal to just change the parameters in the models and fill in the resulting answers. There was very little learning involved. 
Subsequently, it was found that the models were more beneficial to the learning process when used primarily within the classroom and not for assignments. The successful approach was to briefly present an overview of the theory and then ask the class to predict the results if specific changes were made to the parameters of the models. Using this method, near perfect evaluations were obtained (close to 5 out of 5) and the students were very enthusiastic about developing a logical instinct about making economic predictions. Of the many models used the current two-country international trade model and one that modelled the Grossman and Stiglitz (1980) financial market with informed and uninformed investors were the most popular. Some of the students went beyond the course requirements working on the models at their leisure and then bringing interesting questions to the classroom. Though the interactive models have only been in use for several years it has become clear that they are most appreciated by students in an elective course rather than a required core course. An elective course with an enrolment of approximately twenty-five students is an ideal setting. This allows for approximately five teams of five individuals.

Two examples of in-class problems are described below. In working these examples two interesting questions are: (1) To which good would we expect each country to shift its production after going from a closed economy to an open economy and; (2) Which factor of production is likely to gain or lose in each country when going from no trade to free trade? Working extensively with the current model has led to some predictive rules. When going from a closed economy to an open economy, countries tend to produce more of (specialise in) the good that has the lower relative price before trade. In addition, a factor of production will tend to gain (lose) when free trade occurs if the good the country is going to increase (decrease) in production is that which more (less) abundantly rewards that factor of production.

\section{Example One}

Figures 2 and 3 show an initial solution for two countries when they are closed economies and then after trade takes place. Table 1, Example 1, provides the parameter values and outcomes. In using the Excel model the questions submitted to the students is not: what will certainly happen when two countries begin to trade? Nor is it: what could possibly happen when two countries begin to trade? The useful question is: what is most likely going to happen? It is important to remind the students that a simulation model cannot provide universal conclusions.

Figure 2: Country 1

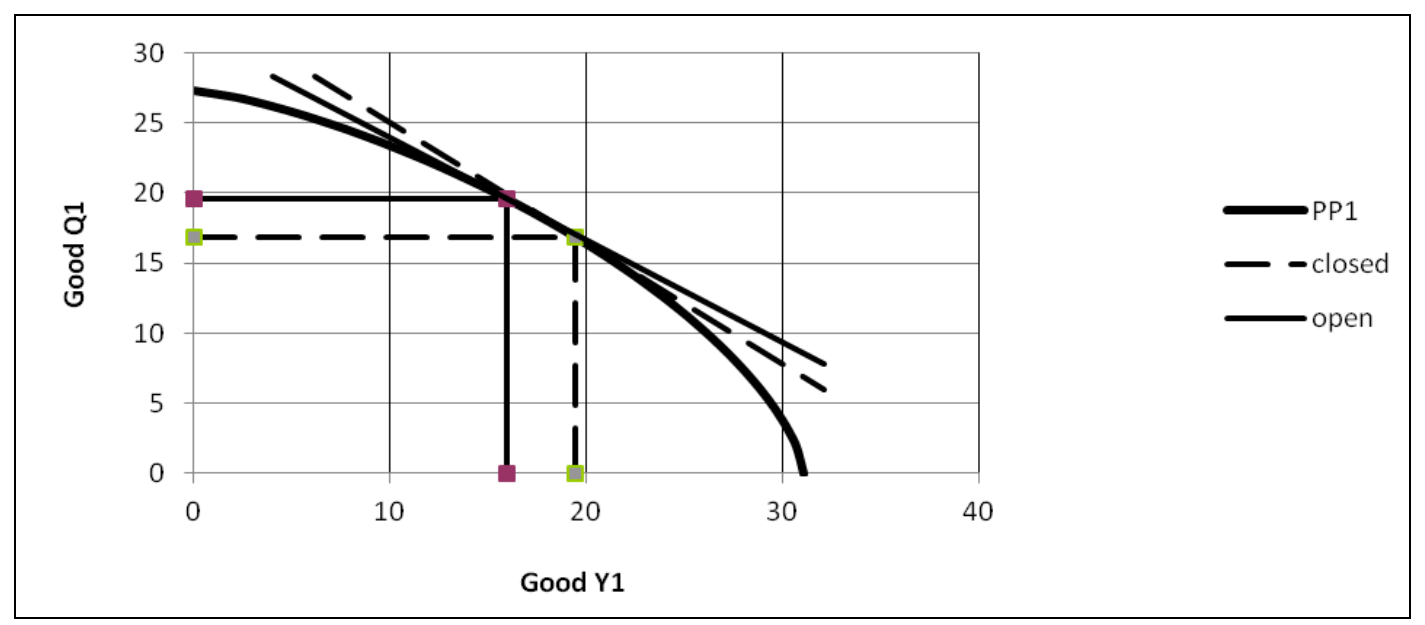


Figure 3: Country 2

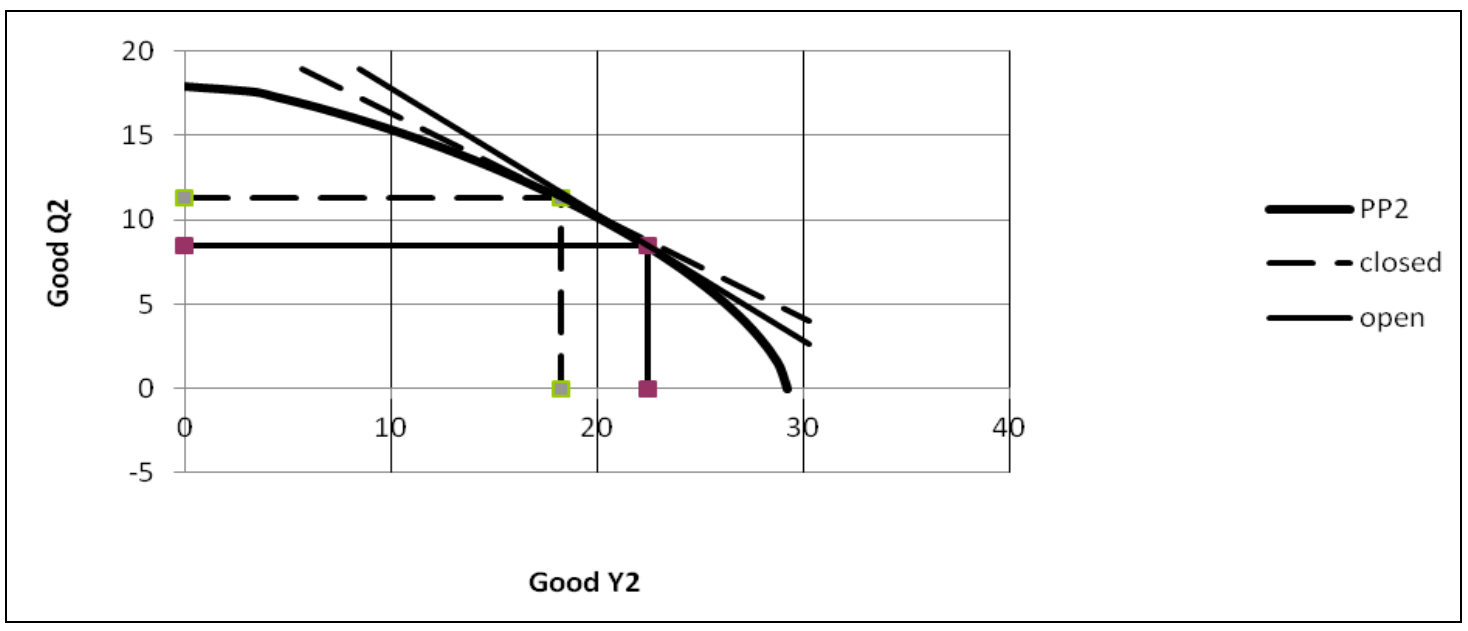

Table 1: Country 2

Exercise 1

Exercise 2

Parameters Country 1 Country 2 Parameters Country 1 Country 2

\begin{tabular}{cccccc}
\hline $\mathrm{Lb}$ & 600 & 80 & $\mathrm{Lb}$ & 600 & 80 \\
$\mathrm{~Kb}$ & 20 & 100 & $\mathrm{~Kb}$ & 20 & 100 \\
$\alpha$ & 0.4 & 0.4 & $\alpha$ & 0.55 & 0.55 \\
$\beta$ & 0.25 & 0.25 & $\beta$ & 0.7 & 0.7 \\
$\mathrm{a}$ & 0.35 & 0.35 & $\mathrm{a}$ & 0.35 & 0.35 \\
$\mathrm{~b}$ & 0.4 & 0.4 & $\mathrm{~b}$ & 0.4 & 0.4 \\
$\mathrm{~s}$ & 0.5 & 0.5 & $\mathrm{~s}$ & 0.5 & 0.5 \\
$\mathrm{t}$ & 0.5 & 0.5 & $\mathrm{t}$ & 0.5 & 0.5 \\
$\mathrm{w}$ & 0.5 & 0.5 & $\mathrm{w}$ & 0.5 & 0.5 \\
$\mathrm{x}$ & 0.5 & 0.5 & $\mathrm{x}$ & 0.5 & 0.5 \\
$\mathrm{~A}$ & 1 & 1 & $\mathrm{~A}$ & 1 & 1 \\
$\mathrm{~B}$ & 1 & 1 & $\mathrm{~B}$ & 1 & 1 \\
\hline $\mathrm{Changes}$ & Country 1 & Country 2 & $\mathrm{Changes}$ & Country 1 & Country 2 \\
\hline $\mathrm{PY} / \mathrm{PQ}(\mathrm{bt})$ & 0.86 & 0.61 & $\mathrm{PY} / \mathrm{PQ}(\mathrm{bt})$ & 10.24 & 11.09 \\
$\mathrm{PY} / \mathrm{PQ}$ (at) & 0.74 & 0.74 & $\mathrm{PY} / \mathrm{PQ}(\mathrm{at})$ & 10.4 & 10.4 \\
$\Delta \mathrm{U}(\mathrm{L})$ & 0.17 & -0.02 & $\Delta \mathrm{U}(\mathrm{L})$ & -1.49 & 1.41 \\
$\Delta \mathrm{U}$ (C) & -0.01 & 0.28 & $\Delta \mathrm{U}(\mathrm{C})$ & 1.52 & -1.15 \\
$\Delta \mathrm{Q}$ & 2.71 & -2.51 & $\Delta \mathrm{Q}$ & -47.08 & 37.42 \\
$\Delta \mathrm{Y}$ & -3.47 & 3.76 & $\Delta \mathrm{Y}$ & 4.55 & -3.47 \\
$\Delta \mathrm{SWF}$ & -2.24 & 2.96 & $\Delta \mathrm{SWF}$ & 2.5 & -8.08 \\
\hline
\end{tabular}


In Example 1 both countries have the same production functions and labour and capital stock owners have the same preferences in both countries. The difference is in the factor endowments. Country 1 has relatively abundant labour while country 2 has relatively abundant capital stock.

What can we predict when this two-country world shifts from closed economies to open economies? Before international trade the price ratio of good $Y$ for good $Q$, in country 1 , is $\Delta Q_{1} / \Delta Y_{1}=-P_{Y_{1}} / P_{Q 1}=-0.8567$ or $P_{Y_{1}} / P_{Q 1}=0.8567$. The ratio in country 2 is $\Delta Q_{2} / \Delta Y_{2}=-P_{Y_{1}} / P_{Q 1}=-0.608$ or $P_{Y 1} / P_{Q 1}=0.608$. Thus good $Q$ is relatively cheaper in country 1 than in country 2 , or equivalently, good $Y$ is relatively more expensive in country 1 than in country 2 . It is reasonable to assume that after international trade takes place each country will tend to produce more of the good that is relatively cheaper in their country, i.e. where it has a comparative advantage. So country 1 produces more of good $Q$ and less of good $Y$ and country 2 will produce more of good $Y$ and less of good $Q$. This prediction is confirmed in the results shown in Table 1.

The parameters $\alpha$ and " $a$ " in the production function also provide the relative shares of the value of outputs $Q$ and $Y$ respectively that go to labour. Thus $\alpha=0.4$ and $a=0.35$ tells us that labour tends to get a greater share of the value of the output of $Q$ than of $Y$. Thus, in country 1 we would expect labour to benefit from the increase in production of $Q$. Simultaneously, labour will tend to be hurt in country 2 as it reduces its production of good $Q$. We find from Table 1 that this is the actual result. The change in utility for labour is positive in country 1 and negative in country 2 . The opposite results occur for the owners of capital stock. As an added feature we find, using the Negishi measure of social welfare, that country 1 has a net decline and country 2 a net increase.

\section{Example Two}

The parameter values for the second situation are also shown in Table 1, Example 2. For the conservation of space the figures are not shown. Everything is the same as in Example 1 except now there are increasing returns to scale in the production of good $Q$.

Again, the important thing to look at is the relative price ratio of the two goods before free trade takes place since with free trade countries will tend to specialise in the good that is relatively cheaper. We see that in the closed economy situation good $Y$ is the relatively cheaper good in country 1 , $P_{Y} / P_{Q}=10.24$ and good $Q$ the relatively cheaper good in country $2, P_{\gamma} / P_{Q}=11.09$. Thus after free trade takes place country 1 would be expected to produce more of good $Y$ and country 2 to produce more of good $Q$. This is exactly what we find in Table 1, Exercise 2. Country 1 increases its production of $Y$ and country 2 increases its production of good $Q$.

Next, we look at the parameters $\alpha$ and " $a$ ". These represent the shares of the value of goods $Q$ and $Y$, respectively that go to labour. The share of the value of good $Q$ going to labour is $\alpha=0.55$ and the share of the value of output of good $Y$ going to labour is $a=0.35$. Thus labour would prefer to see an increase in the production of good $Q$ where it receives the relatively greater share. When free trade takes place country 1 increases its production of good $Y$ and decreases its production of good $Q$. This, in essence, is expected to hurt labour in country 1 . On the other hand, country 2 , with free trade, will increase its production of good $Q$ and labour will gain in this country. From table 2 we find that these predictive rules are confirmed in the analysis. Labour loses and capital stock owners gain in country 1 with the presence of free trade. The opposite holds true for country 2 . Also in this example the net change in Negishi's measure of social welfare favours country 1 over country 2.

\section{Conclusion}

The above model was developed to show the students the outcomes of going from a closed economy to a free trade economy. Unlike the traditional model, which assumes the existence of social indifference 
curves, the current applied model is based on the Samuelson/Jones (1971) theoretical models that present closed systems without the assumption of social indifference curves. At every point on the production possibility curve the combination of goods produced also generate incomes to the factors of production. Given preferences by representative labour and capital stock owners there is an associated demand for the goods produced. In a closed economy the solution in each country is one in which the total demand equals total supply. Where this occurs on the production possibility curve the relative price ratio of the two goods can be obtained by computing the slope of the production possibility curve. With free trade the solution changes to one in which the total demand by both countries equals total supply by both countries and the price ratio of the final goods (i.e. slopes of the production possibility curves) are identical in each country.

Using the interactive model the student finds that going from a closed economy to an open economy does not usually make everyone better off. The gains to trade results obtained in the traditional model usually depend on the assumption that there are social indifference curves. Yet no such social indifference curves are likely to exist unless they are imposed, such as those of the dictator's in Arrow's impossibility theorem.

Learning how to use interactive economic models in the classroom is as important as developing the model. First, the model has to closely conform to the microeconomic theories upon which it is built. The traditional model with its assumed social indifference curves does not remain honest to its microeconomic foundations.

In the course that used the above model the students were very familiar with the Cobb-Douglas production function and the similar homogeneous utility function. They had already learned about production possibility curves. Second, the models should be used in the classroom with student participation encouraged. Possibly the best way to do this is to allow students to make predictions without the fear of grade repercussions and then provide immediate feedback on the results. Third, the models should be made readily available to the students outside of class, especially for the more interested students, but assignments based on using the models is not likely to lead to successful learning experiences.

The two-country trade model is currently being extended to increase the complete interaction. A programme has been constructed that requires students to rank bundles of two goods. This then generates the parameter values of the utility functions used in the above two-country model. In the same course, the students generate the production function parameters by playing simple games in the classroom. These games involve labour (the students) and some form of capital stock. For example one, "paper-throw" game that has been successful requires adding students and crumbled papers (balls) and throwing these into a basket at ten feet. By varying the number of students and balls and then counting the number of baskets per minute, enough data is collected to estimate the Cobb-Douglas production function. The output is made representative of one of the goods in the PP curve. Other different games or separate experiments with the "paper throw" game can be used to generate the production parameters of the second good. When all is complete and tested the students will, in essence, have created enough data to solve a domestic PP curve. By dividing the class into two countries, or in some cases using two separate classes we are able to repeat this operation. Then we can show the final results of closed and open economies. 


\section{References}

Arrow, K. (1951). Social Choice and Individual Values, New York: Wiley.

Grossman, S. and Stiglitz, J. (1980). 'The Impossibility of Informationally Efficient Markets', The American Economic Review, Vol. 70(3), pp. 393-408.

Hamlen, W. and Hamlen, K. (2006). 'A Closed System of Production Possibility and Social Welfare', Computers in Higher Education Economics Review, Vol. 18(1), pp. 15-18.

Jones, R. W. 'A Three-Factor Model in Theory, Trade and History', in J. Bhagwati, R. Jones, R. Mundell and J. Vanek (eds.) (1971), Trade, Balance of Payments and Growth, Amsterdam: North-Holland.

Murphy, B. (1995). 'Examples for Economists with DERIVE'M General Equilibrium for a Cobb-Douglas Exchange Economy', Computers in Higher Education Economics Review, Vol. 9(3).

Negishi, T. (1960). 'Welfare Economics and the Existence of an Equilibrium for a Competitive Economy', Metroeconomics, Vol. 12(2-3), pp. 92-97.

Tohamy, S. M. and Mixon, J.W. Jr. (2003). 'Lessons from the Specific Factors Model of International Trade', Journal of Economic Education, Vol. 34(2), pp. 139-50.

Tohamy, S. M. and Mixon, J.W. Jr. (1999). 'The Heckscher-Ohlin Model with Variable Input Coefficients in Spreadsheets', Computers in Higher Education Economics Review, Vol. 13(2).

Samuelson, P.A., (1971). 'Ohlin Was Right', The Swedish Journal of Economics, Vol. 73(4), pp. 365-84.

\section{Contact details}

Professor Kevin Hamlen, Rm. ECSS 3.704, Computer Science Dept., EC31 800 W. Campbell Rd, University of Texas at Dallas Richardson, Texas 75080-3021, United States of America Email: $\underline{\text { hamlen@utdallas.edu }}$

Professor William Hamlen, Jacobs 244, School of Management, SUNY/Buffalo Buffalo, New York 14260, United States of America Email: $\underline{\text { mgthamle@buffalo.edu }}$ 